\title{
Erlotinib-associated acute pneumonitis: Report of two cases
}

\author{
Bobbak Vahid $M D^{1}$, Ali Esmaili $M D^{2}$
}

B Vahid, A Esmaili. Erlotinib-associated acute pneumonitis: Report of two cases. Can Respir J 2007;14(3):167-170.

\section{Une pneumonite aiguë associée à l'erlotinib : Le rapport de deux cas}

Key Words: Drug-induced lung injury; Epidermal growth factor receptor inhibitor; Erlotinib; Interstitial lung disease; Pneumonitis

\begin{abstract}
Two cases of erlotinib-associated acute pneumonitis are described. The first patient was started on erlotinib treatment for metastatic non-small cell lung cancer. The second patient was treated with erlotinib for metastatic adenocarcinoma of unknown origin. Both patients developed dyspnea and hypoxemia five to six days after initiation of erlotinib treatment. In both cases, computed tomography scan of the chest showed extensive bilateral ground-glass infiltrates consistent with pneumonitis. In both patients, acute pneumonitis resulted in respiratory failure requiring intubation and mechanical ventilation. Diffuse alveolar hemorrhage was excluded by bronchoscopy in both cases. Bronchoalveolar lavage cultures were negative. Erlotinib treatment was stopped and both patients were treated with corticosteroids. The first patient improved gradually and finally was discharged to a rehabilitation centre, but unfortunately the second patient died of Klebsiella sepsis. Naranjo causality scale in both cases suggested a probable association between erlotinib and pneumonitis. Literature on erlotinib-associated pneumonitis is sparse. The clinical presentation and radiographic findings of erlotinibassociated acute pneumonitis are described.
\end{abstract}

On décrit deux cas de pneumonite aiguë associée à l'erlotinib. Le premier patient avait entrepris un traitement à l'erlotinib en raison d'un cancer bronchopulmonaire métastatique non à petites cellules. Le deuxième l'avait commencé en raison d'un adénocarcinome métastatique d'origine inconnue. Les deux patients se sont mis à faire de la dyspnée et de l'hypoxémie de cinq à six jours après le début de ce traitement. Dans les deux cas, la tomodensitométrie du thorax a révélé la présence d'infiltrats bilatéraux étendus « en verre dépoli », compatibles avec une pneumonite, et la pneumonite aiguë a provoqué une insuffisance respiratoire exigeant une intubation et une ventilation mécanique. Chez les deux patients, une bronchoscopie a permis d'écarter la possibilité d'hémorragie alvéolaire diffuse. La culture bronchopulmonaire par lavage était négative. Les deux patients ont abandonné l'erlotinib et entrepris un traitement aux corticoïdes. L'état du premier patient s'est amélioré graduellement, et il a été transféré à un centre de réadaptation. Malheureusement, le second patient est mort d'une septicémie à Klebsiella. Dans les deux cas, l'échelle de causalité de Naranjo laisse supposer une association entre l'erlotinib et la pneumonite. Les publications sont rares au sujet de la pneumonite associée à l'erlotinib. On décrit la présentation clinique et les observations radiographiques de la pneumonite aiguë associée à l'erlotinib.

\section{CASE PRESENTATIONS}

\section{Case 1}

A 66-year-old African-American man presented to the emergency department with dyspnea and dry cough. He had an oxygen saturation of $83 \%$ on room air. Four months before presentation, the patient was diagnosed with metastatic nonsmall cell lung cancer (NSCLC). The patient was started on $150 \mathrm{mg}$ of erlotinib daily, five days before presentation after failure of carboplatin and paclitaxel chemotherapy three months earlier. Two days before presentation, a dry cough and a lowgrade fever were reported by the patient. He experienced worsening of the cough and dyspnea. The patient was an ex-smoker. Physical examination revealed a temperature of $37.7^{\circ} \mathrm{C}$, a blood pressure of $127 / 65 \mathrm{mmHg}$, a respiratory rate of 24 breaths/min and a heart rate of 88 beats/min. Chest auscultation was significant for bilateral diffuse crackles, and jugular venous distention was not present. A chest radiograph showed bilateral alveolar-patterned lung opacifications (Figure 1A).
An echocardiogram showed normal left ventricular systolic and diastolic functions and a computed tomography (CT) scan of the chest showed bilateral ground-glass infiltrates (Figure 2A). Pulmonary embolism was not seen on a CT angiogram of the chest. The patient developed respiratory failure and subsequently intubation and mechanical ventilation became necessary. Bronchoscopy showed no evidence of diffuse alveolar hemorrhage (DAH). Bronchoalveolar lavage (BAL) cultures were negative for bacterial, viral, Legionella, Mycobacterium and fungal pathogens. BAL total cell count was $117 \times 10^{5}$ cells $/ \mathrm{mL}$ and BAL differential cell count showed $76 \%$ neutrophils. Erlotinib-associated acute pneumonitis was diagnosed and $250 \mathrm{mg}$ of methylprednisolone intravenously, every $6 \mathrm{~h}$ for three days, was started. Corticosteroid therapy was continued with $60 \mathrm{mg}$ of prednisone daily thereafter. Hypoxemia improved after four days and the patient was extubated. A repeat chest radiograph showed marked reduction of the bilateral lung opacities. Two weeks after presentation, the

${ }^{1}$ Department of Pulmonary and Critical Care Medicine; ${ }^{2}$ Department of Medicine, Thomas Jefferson University, Philadelphia, Pennsylvania, USA. Correspondence: Dr Bobbak Vahid, Thomas Jefferson University, 1015 Chestnut Street, Suite M-100, Philadelphia, Pennsylvania 19107, USA. Telephone 215-955-6591, fax 215-955-0830, e-mail Bobbak.vahid@mail.tju.edu 


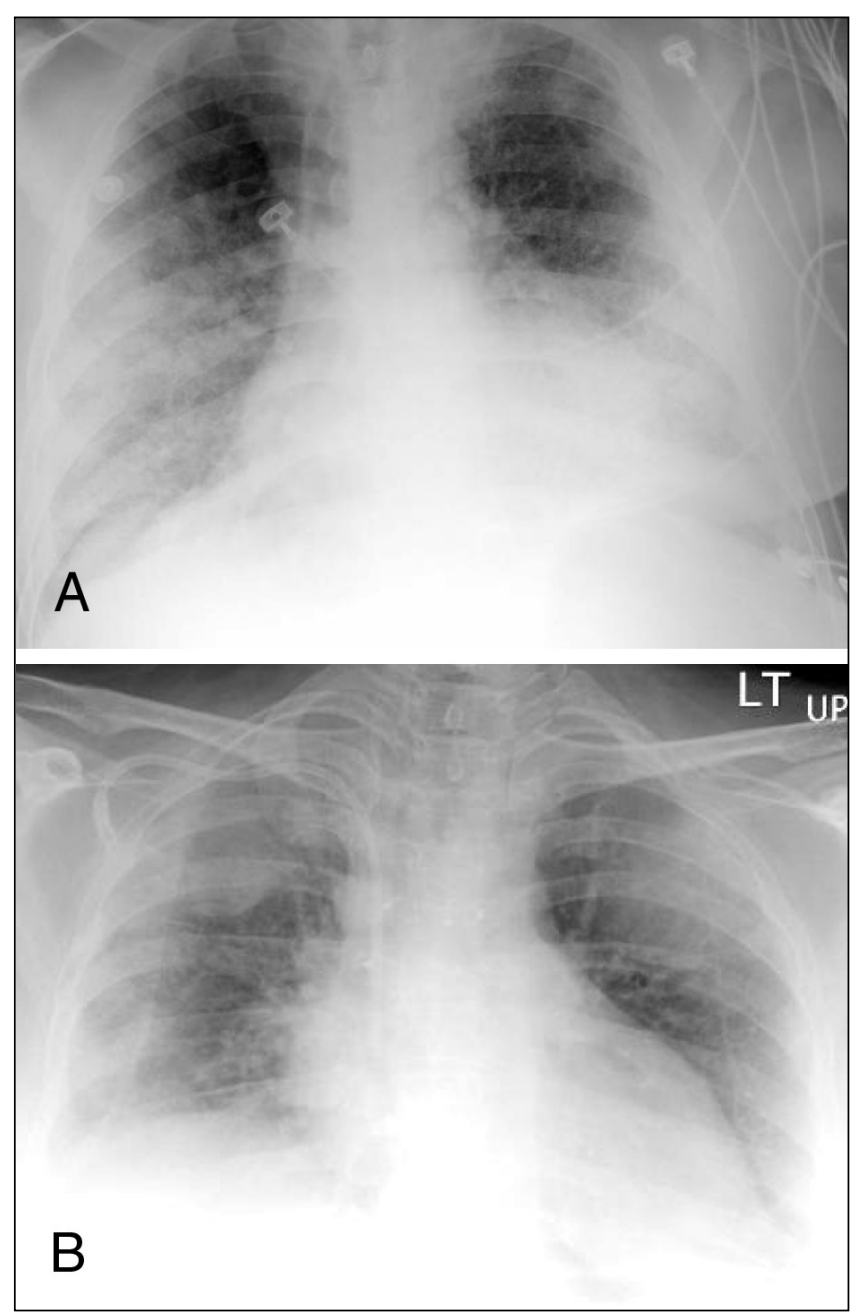

Figure 1) Chest radiographs showing bilateral alveolar-patterned lung opacifications (ie, air-space disease) in patient 1 (A) and patient 2 (B)

patient was transferred to a rehabilitation centre on tapering prednisone. He still required supplemental oxygen at rest.

\section{Case 2}

The second patient was a 46-year-old Caucasian woman who presented to the emergency department with low back pain and weakness of the lower extremities. She had been diagnosed with metastatic adenocarcinoma of unknown origin two weeks earlier. She had involvement of thoracic spine, lumbar spine, ribs and liver. Magnetic resonance imaging of the spine revealed metastatic disease with pathological fracture of the sixth thoracic vertebra and mild cord compression. Palliative radiotherapy (total dose of $20 \mathrm{~Gy}$ ) to the sixth thoracic vertebral lesions was given. The patient refused standard chemotherapy. Erlotinib was offered to the patient as an alternative. She decided to start treatment with $150 \mathrm{mg}$ of erlotinib daily. Four days after initiation of erlotinib, she developed lowgrade fever and dry cough. On day 6 of erlotinib treatment, she experienced worsening of cough and became progressively short of breath. The patient was a life-long nonsmoker. Physical examination revealed a temperature of $37.0^{\circ} \mathrm{C}$, a blood pressure of $99 / 64 \mathrm{mmHg}$, a respiratory rate of 30 breaths/min and a heart rate of 120 beats/min. Oxygen saturation was $87 \%$

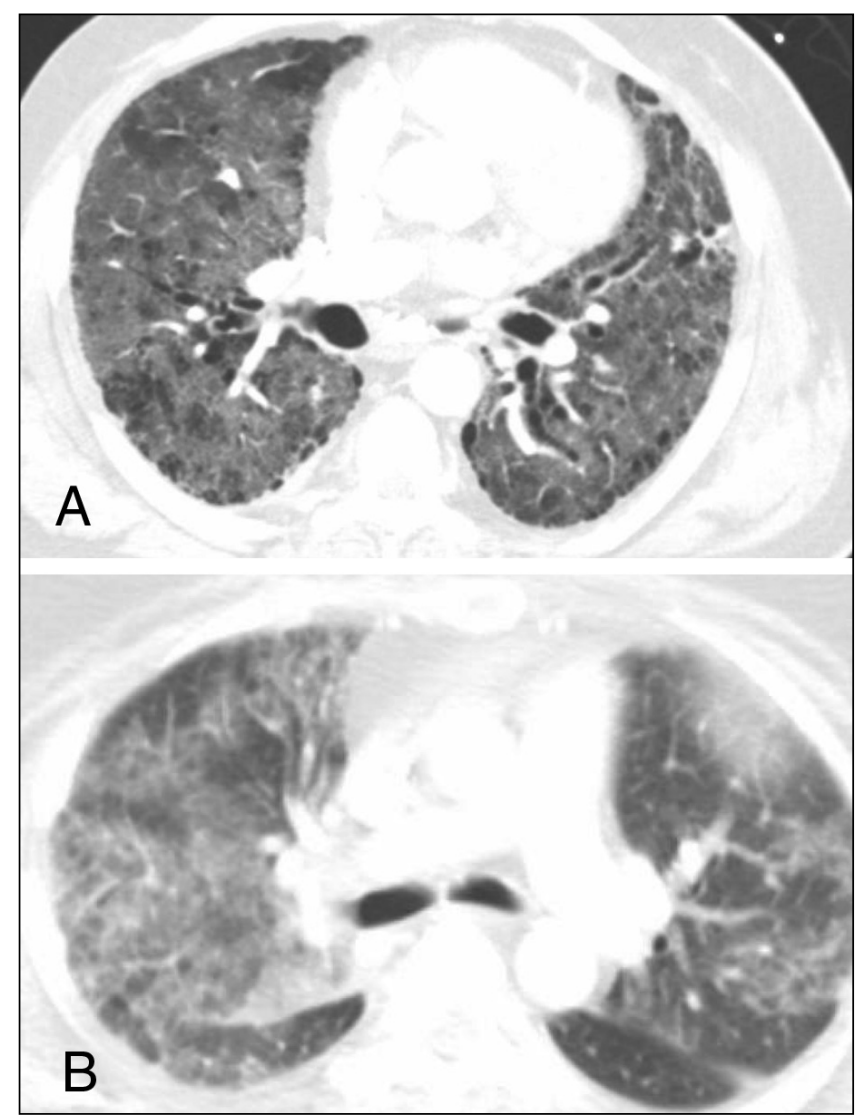

Figure 2) Computed tomography scans of the chest showing diffuse ground-glass infiltrates in patient 1 (A) and patient 2 (B)

on room air. Chest auscultation was significant for bilateral diffuse crackles, and jugular venous distention was not present. Cardiac and abdominal examinations were unremarkable. A chest radiograph showed diffuse bilateral alveolar-patterned lung opacifications (Figure 1B). A CT scan of the chest showed bilateral ground-glass infiltrates (Figure 2B). Pulmonary embolism was not seen on a CT angiogram of the chest. The patient was intubated for progressive respiratory failure and transferred to the intensive care unit. DAH was ruled out by bronchoscopy. BAL cultures were negative for known respiratory pathogens. BAL total cell count was elevated at $155 \times 10^{5}$ cells $/ \mathrm{mL}$ and BAL differential cell count showed $89 \%$ neutrophils. Erlotinib-associated acute pneumonitis was diagnosed and $250 \mathrm{mg}$ of methylprednisolone intravenously, every $6 \mathrm{~h}$ for three days, was started. Methylprednisolone was gradually tapered. Transient improvement in pulmonary status and oxygenation was achieved with corticosteroid therapy, but unfortunately she developed Klebsiella sepsis that resulted in septic shock with multiorgan failure and eventual death. An autopsy revealed diffuse alveolar damage of the lungs, which most likely represents acute lung injury secondary to septic shock.

\section{DISCUSSION}

Drug-associated interstitial lung disease (ILD) is more commonly recognized as a cause of infiltrative lung disease and respiratory failure in patients with NSCLC (1). The differential diagnosis of drug-associated ILD is extensive and includes 
radiation-induced lung injury, pneumonia, cardiogenic pulmonary edema, DAH and lymphangitic carcinomatosis. These conditions cannot be differentiated based on clinical presentations and radiographic findings (2). In our two cases, cardiogenic pulmonary edema was excluded by the finding of normal left ventricular function on echocardiogram. Bronchoscopy with BAL has a high sensitivity for detecting pulmonary infection. In both cases, antibiotics were not given before bronchoscopy and BAL. Negative BAL cultures in our patients made pneumonia an unlikely cause for their respiratory failure. DAH was essentially excluded by the return of nonhemorrhagic BAL. Although the patient in case 2 was treated with palliative radiation to the sixth thoracic vertebra and radiotherapy, which may cause minimal local lung damage in the radiation field, diffuse pneumonitis cannot be explained by radiation injury. Lymphangitic carcinomatosis has a more indolent course and is an unlikely explanation for rapidly progressive respiratory failure in these cases. The development of pneumonitis shortly after initiation of treatment with erlotinib, a lack of an alternative explanation, and the resolution of pneumonitis after corticosteroid treatment and withdrawal of erlotinib, support the diagnosis of drug-induced pneumonitis (probable causality based on the Naranjo scale). Increased BAL total cell count and BAL neutrophilia suggest neutrophilic alveolitis, which is seen in drug-associated pneumonitis $(1,2)$.

Erlotinib is a new human epidermal growth factor receptor type 1/epidermal growth factor receptor (EGFR) tyrosine kinase inhibitor. Erlotinib is indicated for the treatment of patients with locally advanced or metastatic NSCLC after failure of at least one previous chemotherapy regimen (3). More research is also ongoing to define the role of erlotinib therapy in other malignancies, including renal cell carcinoma (4), recurrent or metastatic squamous cell cancer of the head and neck (5), malignant glioma (6), advanced ovarian carcinoma (7), advanced pancreatic cancer (8) and advanced hepatocellular cancer (9).

Pulmonary toxicities have been infrequently reported in patients receiving erlotinib for the treatment of advanced solid tumours (8,10-15). A double-blind, multicentre, randomized trial that was performed by National Cancer Institute of Canada Clinical Trials Group compared orally administered erlotinib (150 mg daily) with placebo. Patients with locally advanced or metastatic NSCLC after failure of at least one previous chemotherapy regimen were enrolled in this study. Overall, the incidence of ILD in this study was approximately $0.8 \%$. Patients in the placebo group had a similar incidence of ILD. In this report, included cases were described in nonspecific terms, such as interstitial pneumonia, alveolitis, pneumonitis and pulmonary fibrosis (3). In a phase III trial of erlotinib hydrochloride (OSI-774) combined with carboplatin and paclitaxel chemotherapy in advanced NSCLC (TRIBUTE), patients were randomly assigned to receive either a daily dose of $150 \mathrm{mg}$ of erlotinib or a placebo concurrently with chemotherapy. There were five severe ILD cases in the erlotinib arm $(1.0 \%)$, versus one ILD case in the placebo arm $(0.2 \%)$. All six cases of ILD were fatal. The clinical presentation and the nature of these ILDs were not reported (12). Erlotinib treatment in the management of previously treated stage IIIB or IV NSCLC was evaluated in another randomized, placebo-controlled, double-blind trial (13). Patients were enrolled in the trial at least 21 days after chemotherapy and one week after radiotherapy. The patients were randomly assigned to the erlotinib arm (150 mg of erlotinib daily) or placebo arm. Three cases of pneumonitis were reported in each of the two groups (13). Risk factors for EGFR tyrosine kinase inhibitor-associated ILD are not well defined. Gefitinib is another EGFR tyrosine kinase inhibitor that has been used in the treatment of advanced NSCLC. A high incidence of ILD has been reported in Japan. In a study by Takano et al (14), pre-existing pulmonary fibrosis was a significant risk factor for gefitinib-associated ILD. It is not known whether this observation is also true for erlotinib-associated lung toxicity.

The mechanism of EGFR tyrosine kinase inhibitor-associated ILD is not known. EGF and EGFR have important roles in the maintenance and repair of epithelial tissues by regulating cell migration, differentiation, proliferation and survival. EGFR expression has been observed in type II pneumocytes. Type II pneumocytes are responsible for recovery of normal alveolar architecture after alveolar injury by re-epithelialization and restoration of normal type I pneumocytes (normal alveolar epithelial cells). It is postulated that inhibition of EGFR will partially diminish the ability of type II pneumocytes to respond to injury (1). Increased KL-6 serum level, which is a marker of type II pneumocyte injury, has been described in EGFR tyrosine kinase inhibitor-associated ILD (2). More research is necessary to better define the mechanisms involved in EGFR tyrosine kinase inhibitor-induced lung injury.

Clinical manifestations of erlotinib-associated acute pneumonitis are nonspecific and include fever, dry cough and dyspnea. Fatal cases have been reported. Diffuse ground-glass infiltrates on CT scan of the chest were found in our two cases that are consistent with diagnosis of drug-related pneumonitis. BAL differential cell count showed evidence of neutrophilic inflammation. Although corticosteroids are widely used to treat drug-induced pneumonitis, there are no data regarding the use of corticosteroid therapy in EGFR tyrosine kinase inhibitor-induced pneumonitis. We used $1 \mathrm{~g}$ of methylprednisolone daily, for three days, in our patients with respiratory failure. Lower doses of corticosteroids may be used in less severe cases of pneumonitis (16).

\section{CONCLUSION}

Although the incidence of erlotinib-associated pulmonary toxicity seems to be low, more cases could be expected with increasing number of patients receiving erlotinib. Clinicians should be aware of clinical and radiographic presentation of erlotinib-associated ILD. Erlotinib should be stopped if the patient develops cough and dyspnea. Corticosteroids should be considered after the exclusion of infection, cardiogenic pulmonary edema, DAH and lymphangitic carcinomatosis.

\section{REFERENCES}

1. Higenbottam T, Kuwano K, Nemery B, Fujita Y. Understanding the mechanisms of drug-associated interstitial lung disease. Br J Cancer 2004;91(Suppl 2):S31-7.

2. Camus P, Kudoh S, Ebina M. Interstitial lung disease associated with drug therapy. Br J Cancer 2004;91(Suppl 2):S18-23.

3. Cohen MH, Johnson JR, Chen YF, Sridhara R, Pazdur R. FDA drug approval summary: Erlotinib (Tarceva) tablets. Oncologist 2005; 10:461-6.

4. Mancuso A, Sternberg CN. New treatments for metastatic kidney cancer. Can J Urol 2005;12(Suppl 1):66-70.

5. Soulieres D, Senzer NN, Vokes EE, Hidalgo M, Agarwala SS, Siu LL. Multicenter phase II study of erlotinib, an oral epidermal growth factor receptor tyrosine kinase inhibitor, in patients with recurrent of metastatic squamous cell cancer of the head and neck. J Clin Oncol 2004;22:77-85. 
6. Haas-Kogan DA, Prados MD, Tihan T, et al. Epidermal growth factor receptor, protein kinase $\mathrm{B} / \mathrm{Akt}$, and glioma response to erlotinib. J Natl Cancer Inst 2005;97:880-7.

7. Gordon AN, Finkler N, Edwards RP, et al. Efficacy and safety of erlotinib $\mathrm{HCl}$, an epidermal growth factor receptor (HER1/EGFR) tyrosine kinase inhibitor, in patients with advanced ovarian carcinoma: Results from a phase II multicenter study. Int J Gynecol Cancer 2005;15:785-92.

8. Dargovich T, Patnaik A, Rowinsky EK, et al. A phase I B trial of gemcitabine and erlotinib HCL in patients with advanced pancreatic adenocarcinoma and other potentially responsive malignancies. Proc Am Soc Clin Oncol 2003;22:223. (Abst)

9. Philip PA, Mahoney MR, Allmer C, et al. Phase II study of erlotinib (OSI-774) in patients with advanced hepatocellular cancer. J Clin Oncol 2005;23:6657-63.

10. Yamamoto N, Yamada Y, Shimoyama T, et al. A phase I study of erlotinib $\mathrm{HCl}$ in Japanese patients with various types of solid tumors. Proc Am Soc Clin Oncol 2003;22:225. (Abst)

11. Tan AR, Yang X, Berman A, et al. Evaluation of epidermal growth factor receptor signaling in tumor and skin biopsies after treatment with OSI-774 in patients with metastatic breast cancer. Proc Am Soc Clin Oncol 2003;22:196. (Abst)

12. Herbst RS, Prager D, Hermann R, et al. TRIBUTE: A phase III trial of erlotinib hydrochloride (OSI-774) combined with carboplatin and paclitaxel chemotherapy in advanced non-smallcell lung cancer. J Clin Oncol 2005;23:5892-9.

13. Shepherd FA, Rodrigues Pereira J, Ciuleanu T, et al. Erlotinib in previously treated non-small-cell lung cancer. N Engl J Med 2005;353:123-32

14. Takano T, Ohe Y, Kusumoto M, et al. Risk factors for interstitial lung disease and predictive factors for tumor response in patients with advanced non-small cell lung cancer treated with gefitinib. Lung Cancer 2004:45:93-104.

15. Tammaro KA, Baldwin PD, Lundberg AS. Interstitial lung disease following erlotinib (Tarceva) in a patient who previously tolerated gefitinib (Iressa). J Oncol Pharm Pract 2005;11:127-30.

16. Muller NL, White DA, Jiang H, Gemma A. Diagnosis and management of drug-associated interstitial lung disease. Br J Cancer 2004;91(Suppl 2):S24-30. 


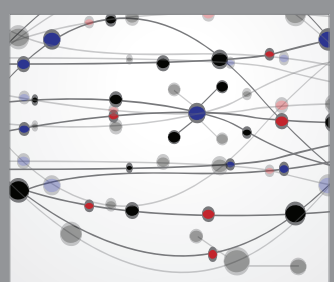

The Scientific World Journal
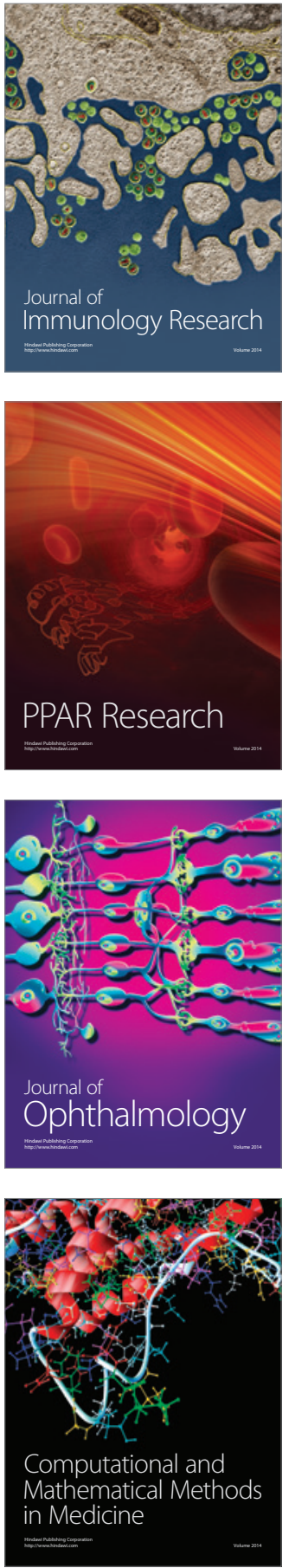

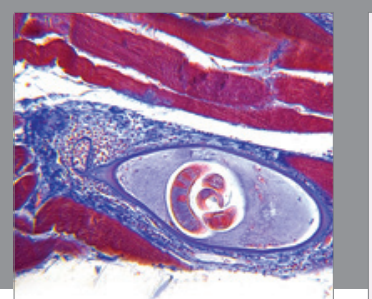

Gastroenterology Research and Practice

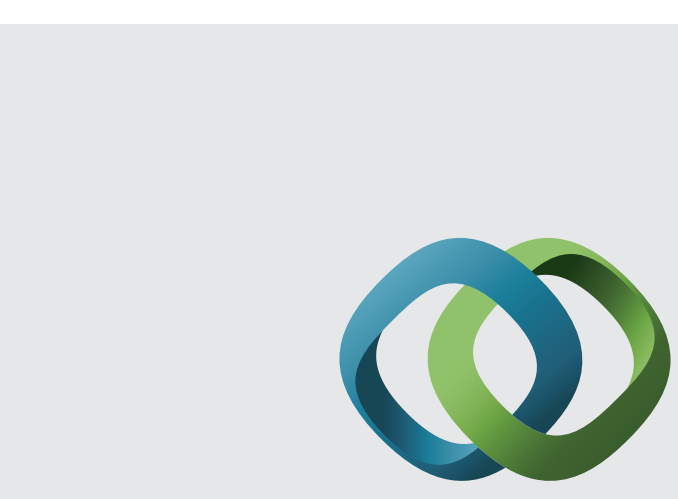

\section{Hindawi}

Submit your manuscripts at

http://www.hindawi.com
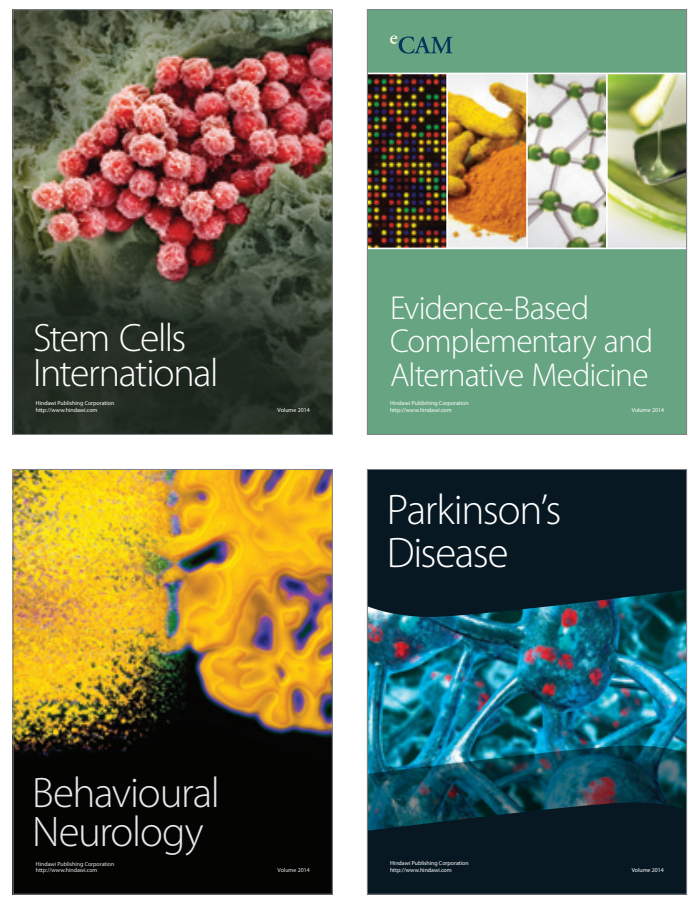
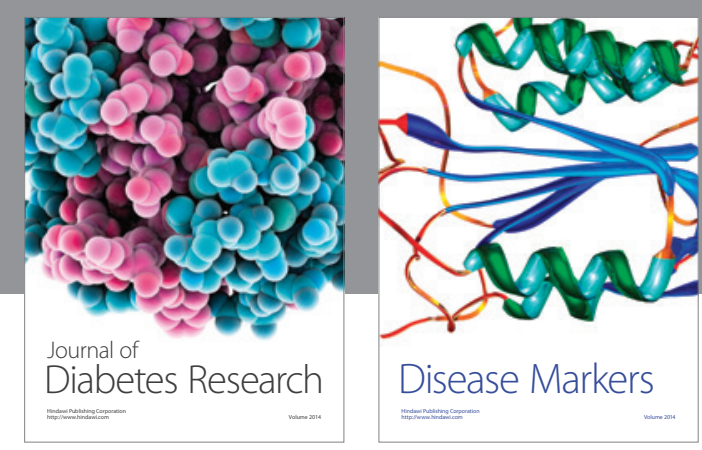

Disease Markers
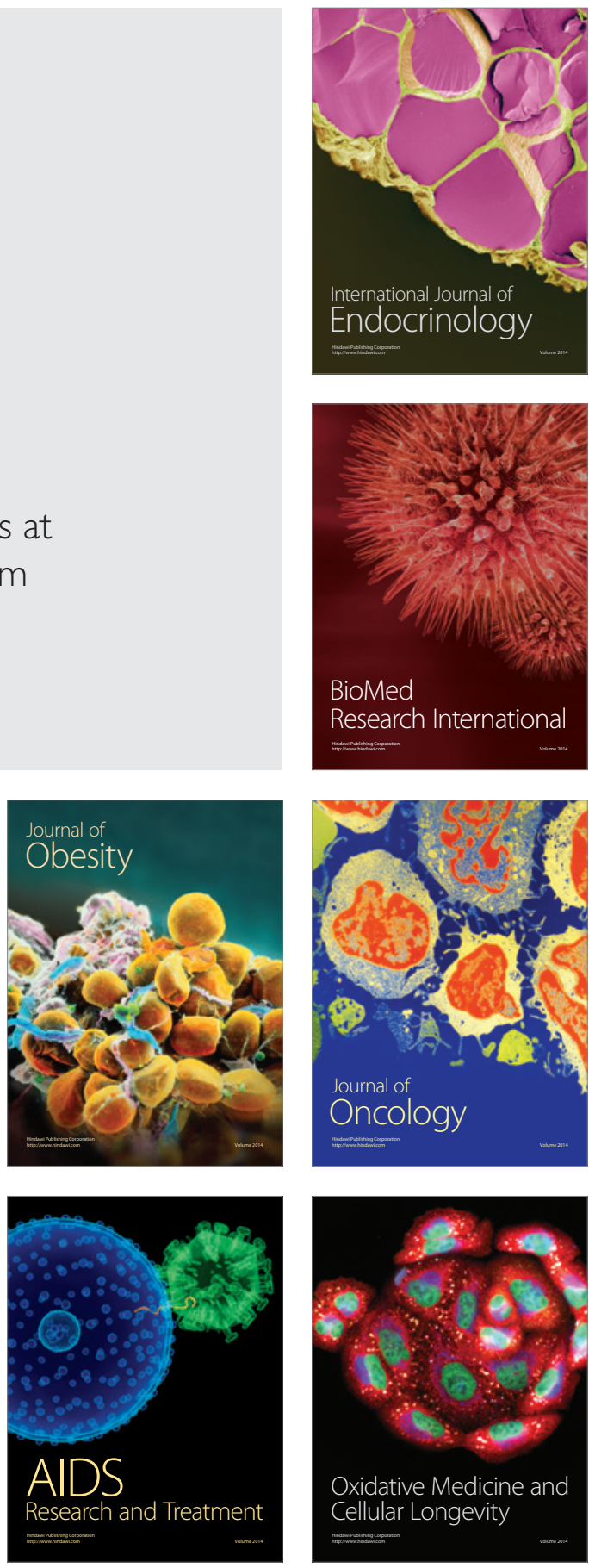